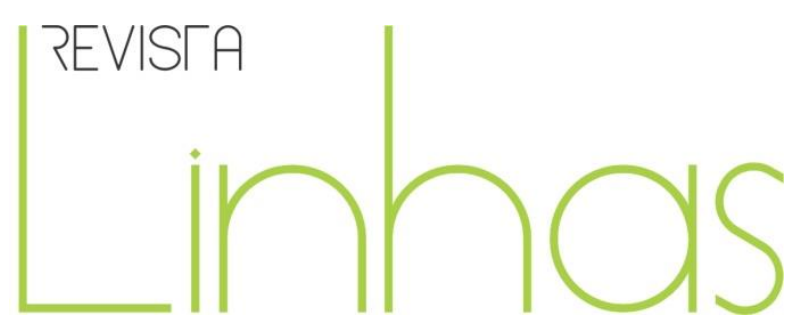

\title{
Resenha do documento "Contribuições para a política nacional: a avaliação em Educação Infantil a partir da avaliação de contexto"
}

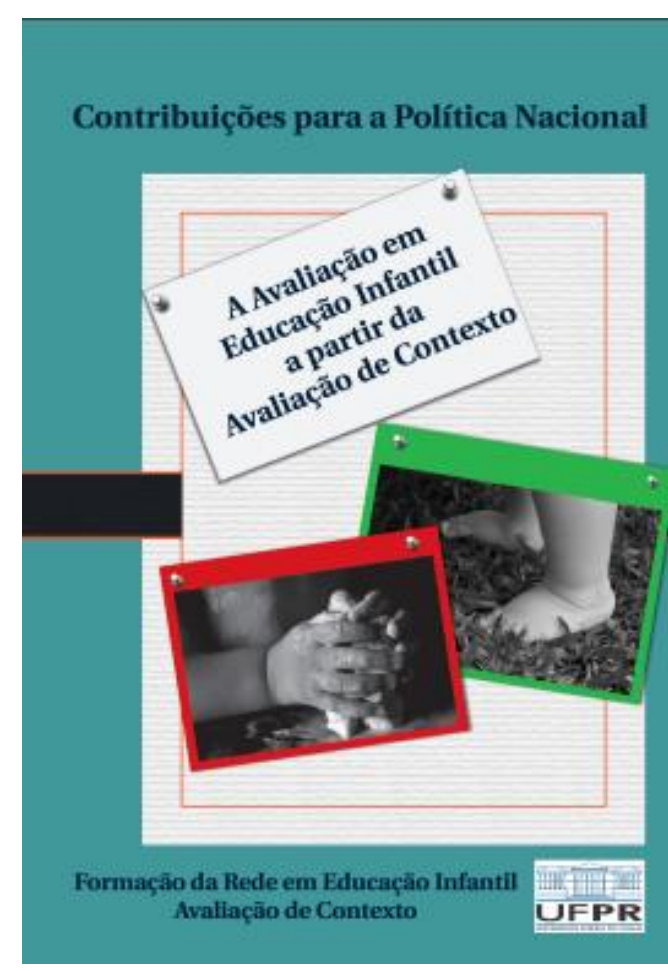

BRASIL. Contribuições para a política nacional - A avaliação em educação infantil a partir da avaliação de contexto. Curitiba: Imprensa/UFPR; Brasília: Ministério da Educação. Secretaria de Educação Básica. Coordenação Geral de Educação Infantil - MEC/SEB/COEDI, 2015, 104p.

Maria Nilceia de Andrade Vieira

Universidade Federal do Espírito Santo - UFES - Brasil

nilceia_vilavelha@hotmail.com

\section{Para citar esta resenha:}

VIEIRA, Maria Nilceia de Andrade. Resenha do documento "Contribuições para a política nacional: a avaliação em Educação Infantil a partir da avaliação de contexto". Revista Linhas. Florianópolis, v. 19, n. 40, p. 455-461, maio/ago. 2018.

\section{DOI: 10.5965/1984723819402018455}

http://dx.doi.org/10.5965/1984723819402018455 
No conjunto de questões polêmicas presentes nas pautas da Educação Infantil brasileira, a temática da avaliação abarca distintos posicionamentos relacionados a concepções, políticas e práticas. Integrando esses debates, o documento Contribuições para a política nacional: a avaliação em Educação Infantil a partir da avaliação de contexto apresenta parte ${ }^{1}$ dos estudos desenvolvidos pelo Projeto "Formação da Rede em Educação Infantil: Avaliação de Contexto". O projeto contou com a parceria técnica e financeira da Secretaria de Educação Básica do Ministério da Educação (SEB/MEC), além de interlocução com a universidade italiana - Università degli studi di Pavia/Itália, tendo sido coordenado pela Universidade Federal do Paraná com a participação de outras três universidades brasileiras (Universidade Federal de Minas Gerais, Universidade Federal do Rio de Janeiro e Universidade do Estado de Santa Catarina). O documento registra "[...] um percurso coletivo de trabalho, uma trama tecida a muitas mãos [...]" (BRASIL, 2015, p. 7) em que o princípio formativo da avaliação perpassa toda a construção da proposta.

Organizado em três partes, o documento, na primeira parte, estabelece relações entre a qualidade na Educação Infantil brasileira e avaliação de contexto. Nesse sentido, pontua a questão da qualidade e da avaliação nos oferecendo um panorama histórico e conceitual que pode ser analisado a partir de diferentes perspectivas. Considerando as ações da COEDI/MEC, o texto situa historicamente a questão da qualidade a partir das mobilizações ocorridas entre os anos de 1970/1980 e realça a elaboração de documentos orientadores pelo MEC, de 1994 até o ano de 2015, que abordam a temática. Nas regulamentações da CEB e do CNE, o documento destaca a publicação das primeiras Diretrizes Curriculares Nacionais para a Educação Infantil nos anos de 1998 e 1999 e sua reformulação em 2009, em um movimento de grande participação e mobilização de diversos setores da sociedade.

\footnotetext{
${ }^{1}$ Exemplos de algumas publicações derivadas do Projeto: SOUZA, Gizele de; MORO, Catarina; COUTINHO, Angela M. S. Formação da rede em educação infantil: avaliação de contexto. Curitiba: Appris Editora, 2015.

MORO, Catarina de Souza; SOUZA, Gizele de. Produção acadêmica brasileira sobre avaliação em educação infantil: primeiras aproximações. Estudos em Avaliação Educacional, São Paulo, v. 25, n. 58, p. 100-125, maio/ago. 2014. Disponível em: <http://www.fcc.org.br/pesquisa/publicacoes/eae/arquivos/1928/1928.pdf>. Acesso em: 24 fev. 2015.

MORO, Catarina; SOUZA, Gizele de. Para uma análise pedagógica dos contextos educativos - uma entrevista com Anna Bondioli, Monica Ferrari e Donatella Savio da Universidade de Pavia/Itália. Educar em Revista, Curitiba, Brasil, n. 60, p. 323-363, abr./jun. 2016. Disponível em: <http://revistas.ufpr.br/educar/article/view/46424>. Acesso em: 25 set. 2016.
} 
No cenário das medidas políticas, o documento registra que, na contramão dessa trajetória de debates, em 2011, a Presidência da República, através da Secretaria de Assuntos Estratégicos (SAE) tenta promover a ampla utilização do instrumento norteamericano, ASQ-3, com o objetivo de avaliar, em larga escala, o desempenho das crianças entre zero e seis anos. Além de salientar os posicionamentos contrários de entidades científicas e movimentos sociais, o documento demarca a ação do MEC e do Instituto Nacional de Estudos e Pesquisas Educacionais Anísio Teixeira (INEP) que, por meio de portarias publicadas em 2011, 2012 e 2013, instituíram Grupos de Trabalho de Avaliação da Educação Infantil e Comissão de Especialistas para elaborar proposta de diretrizes com vistas a compor a política pública nacional de Educação Infantil. Como resultado da produção desses grupos, em 2012 ocorre a publicação do documento Educação Infantil: Subsídios para construção de uma sistemática de avaliação (BRASIL, 2012). Em 2015, é elaborada a proposição de uma minuta de portaria referente à criação da avaliação nacional direcionada ao monitoramento da oferta da Educação Infantil, que aguarda a aprovação do Ministro da Educação.

Quanto à discussão sobre qualidade nos PNE, no primeiro Plano, instituído pela Lei $\mathrm{n}^{\circ}$ 10.172/2001, a qualidade da Educação Infantil constava no texto das metas 10, 11 e 19 sem, contudo, se evidenciar uma busca sistemática por seu efetivo alcance. $O$ atual PNE (Lei $\mathrm{n}^{\circ}$ 13.005/2014) explicita em diferentes artigos, metas e estratégias, os desafios relativos à qualidade e à avaliação relacionadas à gestão democrática, ao financiamento, à ampliação no investimento público em educação, à responsabilidade educacional, ao custo aluno-qualidade, entre outros aspectos. Focalizando os fóruns de pesquisa, a questão da qualidade é tema da Consulta sobre qualidade da Educação Infantil (2006), pela Campanha Nacional pelo Direito à Educação, em conjunto com o Movimento Interfóruns de Educação Infantil do Brasil (MIEIB). A partir de 2010, outras ações, como seminários, encontros e eventos semelhantes vêm sendo promovidas pelo MEC, Fundação Carlos Chagas e Núcleo de Estudos e Pesquisas em Infância e Educação Infantil, da Universidade Federal do Paraná. Além disso, algumas pesquisas evidenciam um crescimento da produção acadêmica em relação à qualidade e à avaliação.

Com base em Bondioli e Savio (2013), o documento ressalta, ainda nessa primeira parte, a relevância da participação dos sujeitos como condição para avaliar a qualidade. 
Enfatiza que essa participação precisa se traduzir em um compromisso entre os sujeitos envolvidos no sentido de definir as ações em conjunto e defende, igualmente, a participação de uma pessoa que possa atuar como formador/facilitador e também avaliador externo.

Pautando-se em uma abordagem avaliativa reflexiva, dialógica, participativa, negociada, democrática e com finalidade formativa, o documento assinala ser imprescindível recorrer a indicadores sistematizados em um ou mais instrumentos e, no caso da pesquisa aqui mencionada, foi feita a opção pelos instrumentos italianos. Com o intuito de avaliar instituições educativas para a infância até os três anos (creches), é utilizado o instrumento ISQUEN - Indicatori e Scala della Qualità Educativa del Nido Indicadores e Escala da Qualidade Educativa da Creche e o instrumento AVSI Autovalutazione della Scuola dell'Infanzia - Autoavaliação da Pré-escola, que destina-se à avaliação de instituições educativas para a infância dos três aos seis anos (pré-escola).

Em direção a um posicionamento acerca da avaliação das crianças a partir da avaliação de contexto no Brasil, as argumentações do documento tomam por base as DCNEI (BRASIL, 2009) quando preveem que a avaliação do percurso proposto pela instituição e vivenciado pelas crianças não deve incluir aspectos relativos à sua promoção, retenção ou seleção, acentuando que “[...] a avaliação de contexto permite problematizar a avaliação da aprendizagem ao colocar os objetivos educacionais alcançados pelas crianças em articulação com a qualidade da formação que elas recebem (o contexto relacional e de aprendizagem oferecidos) [...]" (BRASIL, 2015, p. 40-41).

Na segunda parte do documento, são as questões metodológicas de avaliação formativa de contexto que estão em foco, com análises sobre quem participa e como cada um se compromete com o processo avaliativo em meio a dissensos e confrontos na construção de entendimentos comuns, enfatizando as potencialidades dessa ação avaliativa. Reafirmando a participação como pressuposto basilar da avaliação da qualidade em contexto, o documento situa a pesquisa "Formação da Rede em Educação Infantil: Avaliação de Contexto", desenvolvida no Brasil esclarecendo que a mesma envolveu uma instituição de Educação Infantil pública em cada uma das quatro cidades brasileiras participantes (Curitiba, Belo Horizonte, Rio de Janeiro e Florianópolis). 
Segundo o documento, um dos grandes desafios é a própria concepção de participação, que está diretamente ligada à concepção de democracia. A partir dos pressupostos das pesquisadoras italianas, o documento destaca a participação como elemento que perpassa todo o processo, o que torna primordial o papel do facilitador ou formador no sentido de contribuir para que os participantes compartilhem as diferentes compreensões da realidade na qual atuam e projetem alternativas para o trabalho na instituição.

No compartilhamento do percurso metodológico da pesquisa, o documento detalha as vivências do grupo responsável nas instituições de Educação Infantil que envolveu seis etapas: a plenária inicial, a recolha do "Questionário de Meta-avaliação" (ISQUEN e AVSI), a realização de encontros de discussão acerca de cada instrumento, a observação das turmas de acordo com a(s) área(s) selecionada(s) do instrumento correspondente e os encontros de restituição sobre a observação e pontuação dessas áreas. Esse momento de restituir ao grupo os resultados do processo avaliativo preconiza a explicitação de dissensos e confrontos, aprofundando as razões dos diferentes pontos de vista.

Ao finalizar a segunda parte do documento, o texto aborda as potencialidades do processo de avaliação da qualidade em relação aos desafios e às possibilidades. No âmbito dos desafios estão a organização do tempo, a utilização dos instrumentos e o papel do facilitador/formador. De acordo com o documento, as pesquisadoras assinalam que o modo como o tempo está organizado inviabiliza momentos de estudo no coletivo e sublinham a relevância do papel do facilitador/formador para uma política nacional de avaliação na Educação Infantil, sendo primordial indagar sobre: “[...] Quem ocupará o lugar de facilitador/formador? [...] Quais processos de formação serão necessários? Quem se ocupará de tais processos?" (BRASIL, 2015, p. 55). Quanto às possibilidades, ganha destaque a dimensão formativa da avaliação desenvolvida pelo coletivo ao primar pela democracia e pela participação como pressupostos metodológicos do processo, impulsionando a possibilidade de uma qualidade negociada.

Na terceira e última parte dessa obra, mantendo o tom dialógico do texto, estão expressas muitas vozes constituintes da proposta para elaboração ou revisão de instrumentos de avaliação em Educação Infantil. Essa proposição tem como base 
documentos oficiais brasileiros, a produção bibliográfica das pesquisadoras da Universidade de Pavia (em especial os instrumentos ISQUEN e AVSI) e a documentação da pesquisa de campo produzida pelo Projeto "Formação da Rede em Educação Infantil: Avaliação de Contexto". Assim, em torno do eixo da Experiência Educativa, a proposta avaliativa se organiza a partir de três áreas que incluem subáreas e dimensões.

Essa separação em áreas e subáreas, de acordo com o documento, faz-se necessária devido aos diferentes aspectos referentes à Experiência Educativa que precisam ser organizados, explicitados e destacados ao se desenvolver um processo avaliativo. Nesse sentido, não se pretende imprimir uma perspectiva dicotômica entre princípios e projetos das instituições de Educação Infantil, e sim contemplar elementos que podem estar permeados em diversos itens da proposta avaliativa, assim como podem perpassar itens que compõem mais de uma das áreas, sendo possível, no detalhamento da proposta, perceber diversas conexões entre esses elementos. Nessa perspectiva, as dimensões cumprem valioso papel articulador entre as subáreas e as áreas, nos permitindo pensar em como se entrelaçam nos tempos; nos espaços e materiais e nas relações dialógicas entre professores e crianças.

No conjunto da proposta, a primeira área, que contempla as experiências relacionais e sociais tem como subáreas: inserção, relação e comunicação com as famílias, diversidade e diferenças, cuidado de si, cooperação e participação. A segunda área se direciona a propostas e contextos e inclui as subáreas: interações, brincadeira, manifestações da arte (gestual, dramática, musical, visual), além de narrativas, apreciação e interação com a linguagem oral e escrita. A terceira área, denominada área transversal: organização, reflexão e socialização, contempla as subáreas: observação, planejamento e avaliação. Esta área perpassa as duas outras e todas as subáreas e dimensões, e "[...] assume uma função própria como instrumento que assegura a dinâmica sistêmica necessária à experiência educativa [...]” (BRASIL, 2015, p. 65), referindo-se a modos e ações que subsidiam tais práticas e processos no que se refere às duas primeiras áreas.

$\mathrm{Na}$ extensão limitada desta resenha, reconhecendo que muitas abordagens deixariam de ser contempladas, optamos por evidenciar questões que ampliem os debates e a compreensão acerca das possibilidades da avaliação de contexto na perspectiva de contribuição com a política nacional de Educação Infantil. Isto posto, cabe 
salientar que a obra assume uma predisposição para movimentos dialógicos sobre temáticas polêmicas com base em vivências de instituições que atendem as crianças de zero a seis anos. Nesse propósito, se o contexto brasileiro atual clama por movimentos de resistência a medidas que ameaçam muitos direitos conquistados na trajetória da Educação Infantil, a leitura deste documento constitui-se como possibilidade de fortalecer nosso compromisso com a qualidade educativa em uma perspectiva de participação democrática em processos avaliativos. 